\title{
Development
}

\section{General practitioners with special interests: the potential benefits and possible risks for primary care}

Stephanie Honey, Neil Small School of Health Studies, University of Bradford, Bradford, UK and Shahid Ali Bradford South and West Primary Care Trust, Queensbury, Bradford, UK

\begin{abstract}
General practitioners have always had special interests. Recent policy initiatives in the UK, organizational changes and changing attitudes by the Royal Colleges have meant that there is an increasing interest in the development of a new role for GPs with special interests (GPSIs). This paper considers what methodology is best suited to examining change, while that change is still developing. Specifically, it offers a model that identifies different forms of knowledge; anticipated, explicit and tacit and considers how these can combine in an evaluative model for innovations in primary care. The paper goes on to identify potential benefits and risks of a shift towards GPSIs. It develops a picture of GPSI services in one PCT and focuses on two disciplines, orthopaedic medicine and urology. Views of those GPs providing these services are reported and are linked with the possibilities that a new form of general practice might emerge without general practitioners.
\end{abstract}

Key words: evaluation; general practice; knowledge; primary care trusts; specialists

\section{Introduction}

It has always been the case that individual GPs have been informally regarded as experts in specific areas. For some that expertise, for example in child health, has been more formally recognized by the wider health community. However, it is only recently that the idea of general practice specialists has been formalized. This is a development that resonates with earlier shifts in hospital medicine where the once widespread presence of general physicians and general surgeons has been replaced with specialists in specific disease areas.

The GPSI concept emerged during the period that followed the Working for Patients White

Address for correspondence: Dr Stephanie Honey, School of Health Studies, University of Bradford, 25 Trinity Road, Bradford BD5 0BB, UK. Email: s.a.honey@bradford.ac.uk
Paper (Department of Health, 1989). This introduced 'fund holding' into general practice and hence the ability of GPs to allocate part of their budget as they saw fit. GPs with surgical skills, often gained while working as clinical assistants in hospitals, offered to carry out certain procedures in their own surgeries that had normally been performed in secondary care settings. With the development of fund holding consortia and primary care organizations (PCGs (primary care groups) and PCTs) opportunities to expand these services increased. The NHS Plan (Department of Health, 2001a) identified a clear intent that by 2004 up to 1000 specialist GPs would be taking referrals from fellow GPs. GPSI development is also consistent with the Shifting the Balance of Power (Department of Health, 2001b) agenda, with the aims of the Modernisation Agency (Department of Health, 2001a) and with the achievement of targets - notably reductions in waiting times. An emphasis on flexible working, the primacy of shared care and patient pathways 
Table 1 Benefits and risks of developing GPSIs for different stakeholders

\begin{tabular}{|c|c|c|}
\hline For & Benefits & Risks \\
\hline GPs & $\begin{array}{l}\text { Increase in job satisfaction: improve retention; } \\
\text { reduce burnout: increased financial reward }\end{array}$ & $\begin{array}{l}\text { Lack of clarity about what the skills and } \\
\text { expectations of GPSI are. The risk is both } \\
\text { exploitation of the GP and problems in the } \\
\text { standard of service for the patient }\end{array}$ \\
\hline General practice & $\begin{array}{l}\text { Provide an intermediate tier of advice and } \\
\text { expertise: provide alternate route for referral } \\
\text { and access }\end{array}$ & $\begin{array}{l}\text { Further reduction in the numbers } \\
\text { of generalists }\end{array}$ \\
\hline Trusts & Reduce waiting time and improve access & $\begin{array}{l}\text { Problems in reconciling local need and doctor } \\
\text { preference. Difficulties in incorporating GPSI } \\
\text { work into local clinical governance and risk } \\
\text { procedures }\end{array}$ \\
\hline Patients & $\begin{array}{l}\text { Offer a holistic insight involving 'physical, } \\
\text { psychological and social paradigms' } \\
\text { (Gerada et al., 2002) in areas previously } \\
\text { dominated by hospital based specialists }\end{array}$ & $\begin{array}{l}\text { Reduction in standard of care to patients seen } \\
\text { by non-specialists (because of employment of } \\
\text { locum cover while special interest work is } \\
\text { being undertaken). Reduction in the standard } \\
\text { of care for patients because of level of skill of } \\
\text { GPSI. Specifically as Gerada et al. identify } \\
\text { there is a need to ensure that PCTs are 'not } \\
\text { merely replacing consultant specialist opinion } \\
\text { with a cheaper, less experienced one' } \\
\text { (Gerada et al., 2002) }\end{array}$ \\
\hline
\end{tabular}

and a shift of clinical interventions towards primary care all resonate in the GPSI agenda.

In practice there was already a much more widespread involvement by GPs in specialist services. A 2002 survey identified 16\% of UK GPs, approximately 4000, providing specialist clinical services outside their core general practice commitments (Jones and Bartholomew, 2002).

However, this widespread activity reflected the interests of the GPs rather than any strategic assessment of need. As PCTs commission GPSIs to provide services there is a need to see specialist services as integral to their planning and not just as something primarily concerned with responding to the professional agendas of the GPs and recruitment and retention issues in the practices. Since the publication of The NHS Plan there has been a developing debate about the potential benefits and risks for staff and patients of promoting GPSIs. This paper begins with a summary of this debate. It then:

- reflects on what is an appropriate methodology to assess the impact of innovation in general practice

- provides a detailed picture of the emergence of GPSIs in one PCT.

\section{The potential benefits and possible risks of developing GPSI}

Government policy as evidenced in the NHS Plan and in Shifting the Balance of Power (Department of Health 2001a; 2001b) is supportive of both a blurring of the interface between primary and secondary care and the development of multidisciplinary collaborations. One route to achieve these aims is to create new career structures for GPs. In this context, the Royal College of General Practitioners has seen GPSIs as a way of promoting portfolio careers and, at the same time, maintaining the legitimacy of a generalist mode within general practice (Royal College of General Practitioners and Royal College of Physicians of London, 2001; Royal College of General Practitioners, 2001; Department of Health/Royal College of General Practitioners, 2002).

Potential benefits of developing GPSI services relate to the interests of GPs, of general practice as a mode of care, of trusts and of patients (Table 1).

There are data available on the impact of specialist clinics run by GPs. These data examine patient satisfaction and cost of services (Bowling and Bond, 2001; Rosen and Jones, 2003) and the need for a careful and sustained engagement with all parties 
involved (Sanderson et al., 2003). In some specific areas there are trial data on chronic disease management in primary care led clinics (Fitzmaurice et al., 2000). But the overall conclusion, reached by Rosen et al. (2003), in terms of the likely impact on clinical and cost effectiveness is that the evidence of the impact of GPSIs is 'almost non-existent' (p. 461).

The GPSI service described in this paper was one of the first to be developed in the UK (Richardson, 2002). It was given the status of an NHS Beacon Service in 2001. The Beacon scheme represented a route for transmitting examples of best practice through the NHS. Beacon sites were given funds, typically for two years, to train staff, act as mentors, produce information, and facilitate visits (NHS Executive, 2003). Our question here is, 'how do we know what is "best practice",. This was certainly an innovative scheme and one that proved popular within the PCG, then the PCT, and with a continuing stream of visitors. But it had not been evaluated - it was not evidence based in the sense implied in the 1997 White Paper (Department of Health, 1997) nor being developed in National Service Frameworks and scrutinized via clinical governance. Most innovation in service delivery is not evidence based (Black, 2001). It will take some years to generate conventional evidence. However, it is clear that many people think the scheme works and are keen to learn from it. How can we conceptualize the learning from experience that is assumed in the Beacon scheme and is at the heart of so much health care practice (Small, 2003)?

\section{Anticipated, explicit and tacit knowledge - an epistemology for evaluating innovative practice}

Polanyi (1966) identified two categories of human knowledge. First there is 'tacit' knowledge. This is personal and difficult to formalize or record. The technical aspect of tacit knowledge encompasses personal skills, often referred to as 'knowhow', and can best be transferred via example or apprenticeship. The more cognitive aspects of tacit knowledge include personal beliefs, values and mental models. This cognitive dimension strongly influences the way we perceive our world and can be transferred through conversation and narrative. Tacit knowledge is also referred to as uncodifiable knowledge. Second 'explicit', or codifiable, knowledge can be transmitted via formal, systematic means such as written documents and computer files. This knowledge can be transferred from one person to another without direct interaction or demonstration.

Recent studies have demonstrated that a qualitative approach, which scrutinizes both tacit and explicit knowledge, can be employed to investigate education (Gamble, 2001), business (Hansen et al., 1999), research (Jarvis, 1999), as well as complex health and social interventions including those in primary care (Wyatt, 2001; Rashman and Hartley, 2002; Aita et al., 2003). It is this approach that we propose to follow. We will do this by combining the tacit, informal interviews with GPs and observation carried out in the clinical settings, with the explicit data on the range of services and uptake of them collected from paper documents and electronic sources.

But we want to add the idea of anticipated knowledge. This we borrow from Karl Popper where he described the scientific process as beginning with: 'These marvellously imaginative and bold conjectures or "anticipations" of ours'. These 'are carefully and soberly controlled by systematic tests. Our method of research is not to defend them, in order to prove how right we were. On the contrary we try to overthrow them' (Popper, 1959: 279).

In the NHS, the structure of practice can change when there is a convergence of assumptions and aspirations. Some of these assumptions come from people planning services and some from those delivering services. The assumption that modernization is good and that the balance of services should be shifted; the recognition that something must be changed in order to attract more doctors into general practice; and the need to reduce costs and improve patient satisfaction by treating people in primary care rather than secondary care can push policy-makers and planners to encourage developments like GPSIs. At the same time GPs may be dissatisfied with the structure of their jobs, both in the short and long term, and they exert a pull towards innovative practice. There is then a shared assumption that if GPs are encouraged and supported to become specialists then some of the professional and system aspirations can be met. This process is essentially framed by a coming together of anticipatory (or aspirational) knowledge - that which we wish to 
happen or believe should happen - with tacit knowledge.

In what follows we will highlight how the anticipatory can be interrogated by the explicit. That is, we will describe what the PCT is seeking to do and look at the data that illuminate how far it is achieving its aims. We will then go on to combine the explicit with the tacit. We present figures about how widespread GPSI services are with the impressions of the service champions about its impact. We are not seeking a representative sample or claiming more than that our approach illuminates the Beacon service. Consistent with this, and with the Beacon approach where those involved in the service are charged with disseminating their practice, we identify our informants (with their permission).

\section{The anticipatory and the explicit: the development of GPSIs in Bradford South and West PCT}

Bradford South and West Primary Care Trust provides a service for approximately 147000 people within a large metropolitan borough in the north of England. The trust includes 24 practices with 103 general practitioners, 30 of whom are GPSIs.

The GPSI model was enthusiastically taken up by Bradford South and West PCG and continued after the shift to PCT status (Dhillon and Rout, 2002). The PCG identified GPs with suitable skills and GPSI services were developed in several clinical areas. The development continued as more GPs, with an interest in a particular discipline, enhanced their expertise by undertaking further training and/or worked closely with hospital consultants. In 1999, Bradford South and West PCG was awarded the Service Development Award of the National Association of Primary Care for its work on the role of the GPSI and in 2001, for this same area of work, achieved 'Beacon' status. A Commission for Health Improvement Clinical Governance Review of the PCT in 2003 identified the use of GPs with special interests as 'an area of the PCT's work that the rest of the NHS can learn from' (Commission for Health Improvement, 2003: 4).

Table 2 shows the range of GPSI services offered by Bradford South and West PCT. The

services listed are delivered from two intermediate care centres and 14 GP surgeries. Facilities at the intermediate care centres include consulting rooms, operating theatres and recovery suites. The theatres are fully equipped for day case surgery and diagnostic procedures. Physiotherapists and nurses support the work of the GPSIs. Some nurses specialize in areas such as rheumatology and prostate assessment. Practice nurses support GPSIs who deliver services from their own surgeries. Most GPSIs dedicate 1 day per week to GPSI activities. During this time provision has to be made for the GPs' other patients and this is achieved by employing more staff, such as additional salaried doctors and nurse practitioners, and by extending the roles of nurses and health care assistants. In addition all the GPs within the practices involved agree to arrange their work-loads to provide cover for GPSI work.

At present a GP who is interested in doing GPSI work is asked to apply to the PCT. If the service offered will meet an identified gap in provision, and if it is assessed by the PCT as cost effective, the PCT will support its development. Salaried GPs commencing employment with the PCT are encouraged to undertake GPSI training and it is felt that this aids their recruitment. At board level there is a strong commitment to the development of GPSI services across the PCT.

Clinical governance arrangements for GPSI services include the following:

1) Training: GPSIs are trained by consultants and undertake further qualifications where available. ${ }^{1}$

2) Accreditation and reaccreditation: The present accreditation process for GPs is being extended to include GPSIs.

3) Audit of the procedures or service provided.

4) Patient satisfaction surveys.

Payment for GPSI services is arranged either through contracts or service level agreements. A GPSI working at the intermediate care centre will typically be contracted to work for 52 weeks per

\footnotetext{
${ }^{1}$ From December 2003, GPs can access a University of Bradford accredited postgraduate diploma course for GPSIs with a special interest in cardiology. The course is run by Bradford City PCT and approved by the appropriate Royal Colleges. Other special interests will be added in 2004 and beyond.
} 
Table 2 Range of GPSI services offered by Bradford South and West PCT

\begin{tabular}{|c|c|c|c|}
\hline Service & Procedure & $\begin{array}{l}\text { Number } \\
\text { of GPSIs } \\
\text { offering } \\
\text { service }\end{array}$ & $\begin{array}{l}\text { Number } \\
\text { of } \\
\text { locations }\end{array}$ \\
\hline \multirow[t]{4}{*}{ Minor surgical procedures } & General and orthopaedic ${ }^{a}$ & 12 & 8 \\
\hline & Joint injections & 6 & 4 \\
\hline & Ophthalmic surgery ${ }^{b}$ & 1 & 1 \\
\hline & Vasectomy & 2 & 2 \\
\hline \multirow[t]{7}{*}{ Diagnostic procedures } & 24 hour blood pressure monitoring & 2 & 2 \\
\hline & Cystoscopy & 3 & 3 \\
\hline & ECG reporting & 2 & 2 \\
\hline & Endoscopy & 4 & 2 \\
\hline & Flexible sigmoidoscopy & 1 & 1 \\
\hline & Hysteroscopy & 3 & 1 \\
\hline & Spirometry & 1 & 1 \\
\hline \multirow[t]{5}{*}{ Management of chronic diseases } & Diabetes clinic & 9 & 7 \\
\hline & Drug and alcohol dependence & 3 & 1 \\
\hline & Mental health & 1 & 1 \\
\hline & Neurology including: Parkinson's and epilepsy & 4 & 4 \\
\hline & Pain management & 1 & 1 \\
\hline \multirow[t]{5}{*}{ Triage of outpatient referrals } & Dermatology & 3 & 1 \\
\hline & ENT & 2 & 1 \\
\hline & Gynaecology & 3 & 1 \\
\hline & Paediatric & 1 & 1 \\
\hline & Rheumatology & 2 & 1 \\
\hline
\end{tabular}

${ }^{\mathrm{a}} \mathrm{General}$ and orthopaedic surgical procedures include: injection of haemorrhoids, injection of varicose veins, circumcision, incision abscess/cyst ablation/avulsion of toenail, nasal cautery, minor plastic surgery, dorsal split, carpel tunnel release, trigger finger release.

${ }^{b}$ Ophthalmic surgical procedures include: chalazion/meibomian cyst, expiration of lesion on eyelid, syringing of nasal-lacrimal ducts.

year (including eight weeks holiday). The work would involve 42 weeks of face-to-face consultations with patients and two weeks audit time. A set salary is paid for this work and any additional sessions are paid pro rata. Some GPSIs working in their own practices are remunerated via a service level agreement and agree to provide the PCT with a certain number of consultations or procedures.

To give some insight into the detailed implementation and impact of GPSI's the rest of this article will focus on two GPSI disciplines: orthopaedic medicine and urology.

\section{The explicit and the tacit: the detail of specific initiatives and the impressions of their impact}

\section{Orthopaedic medicine}

Two GPSIs, Drs Ann Connolly and Andy Booth, provide an orthopaedic medicine service in one of the intermediate care centres. The service was set up in 2000 and, initially, only rheumatology patients were seen. In 2002 patients with musculoskeletal problems were also treated. Today a nurse practitioner (a rheumatology specialist nurse) and two physiotherapists make up a multidisciplinary team. Rheumatology and orthopaedic patients are referred by any GPs in the PCT. The team perform a triage service, as well as treating and managing the care of appropriate patients. Dr Booth runs a rheumatology clinic at his own practice. Here, patients with rheumatoid arthritis who are on DMARDs (disease-modifying antirheumatic drugs) are closely monitored by himself and his practice nurse. He also carries out minor surgery and joint injections.

Once a week the teams meet and read all referral letters. There can be between 20 and 35 each week. A decision is made at this triage meeting as to the best course of action in each case. Possible actions include: 
Table 3 Referral patterns from the GPSI orthopaedic medicine service

\begin{tabular}{|c|c|c|c|c|c|c|}
\hline Date & Nature of service & $\begin{array}{l}\text { No. of } \\
\text { patients } \\
\text { triaged } \\
\text { by GPSIs }\end{array}$ & $\begin{array}{l}\text { No. of } \\
\text { patients } \\
\text { referred } \\
\text { to GPSIs }\end{array}$ & $\begin{array}{l}\text { No of } \\
\text { patients } \\
\text { treated by } \\
\text { intermediate } \\
\text { care physios }\end{array}$ & $\begin{array}{l}\text { No. of patients } \\
\text { referred on to } \\
\text { secondary care }\end{array}$ & $\begin{array}{l}\text { No. of patients } \\
\text { referred to Dr Frazer }\end{array}$ \\
\hline Feb. 2000-Nov. 2001 & Rheumatology only & 375 & 337 & 0 & 38 & 0 \\
\hline Jan. 2002-Jun. 2002 & $\begin{array}{l}\text { Rheumatology and } \\
\text { Orthopaedics }\end{array}$ & 566 & 200 & 224 & 110 & 32 \\
\hline
\end{tabular}

1) Treatment by a GPSI, physio or nurse practitioner (or any combination of the three) at the intermediate care center.

2) Referral to Dr Keith Fraser - another GPSI with a special interest in minor orthopaedic surgery.

3) Referral to a consultant rheumatologist.

4) Referral to a consultant orthopaedic surgeon.

5) Referral to a hospital physiotherapist.

The numbers of patients referred to each of the above are presented in Table 3.

Dr Ann Connolly gave some examples:

If a chap has tennis elbow and he has had three previous injections it is clear he needs an operation and he will be sent straight to the orthopaedic surgeons. If someone has osteoarthritis of the knee and possibly needs a knee replacement, they see the physio first and they assess them according to a scoring sheet. If a patient has generalized joint pains, possible rheumatoid arthritis, then Dr Booth and I see them and we will either decide that they don't have an inflammatory arthritis or if they do we do all the tests and then either start the treatment or send them on to the hospital. So by the time they get to the hospital they have already been 'worked up'. If someone has clearly got rampant lupus we just send them straight to hospital.

The rationale behind the system is to:

1) Shorten the time a patient has to wait to be treated.

2) Ensure that consultants receive only 'high quality' referrals.

3) Ensure that necessary investigations (such as MRI scans and blood tests) can be arranged before the patient is seen by a consultant.
Before this system was set up many patients gained no more from their appointment with a consultant than to be told they had to have an investigation or see a physiotherapist. The intermediate care team can also directly access appliances and podiatry services.

\section{What difference does the orthopaedic medicine service make?}

Dr Ann Connolly was interviewed about the impact of the service. She emphasized that she believed consultants are more likely to receive high quality referrals:

The main aim is to stop the consultants seeing inappropriate referrals. At the end of the day the orthopaedic surgeons should only see patients that need an operation and the rheumatologists should only see patients who need a second line agent and need to be monitored by a practice nurse.

Since the GPSI rheumatology service started the waiting time to see a consultant rheumatologist has gone down from three months to two weeks, for one consultant, and from six months to three months, for another:

Two years ago when we first set this up Dr Booth and I did a waiting list initiative and we did some extra sessions for the ' 6 month waiters' - well there are none now.

Dr Ann Connolly

In conjunction with reduced waiting times the reassurance that patients receive from GPSIs is very beneficial:

A lot of the time we reassure people that they haven't got rheumatoid arthritis. They 
think they have because they have joint pains but we do the tests and say 'no - let's work on what you have got'. It saves them months of worry.

\section{Dr Ann Connolly}

Further benefits to patients include:

The intermediate care centre is nicer (than the hospital), its local, its dedicated time my phone doesn't ring with anything else and the appointment is slightly longer. We know local GPs and local services.

\section{Dr Ann Connolly}

While the GPSI's knowledge of the area, and sometimes of the patients and their family, can be a help it can also be beneficial for some patients to see a GP other than their own. This doctor may have a more objective view about the presenting problem:

Some patients may have done the rounds before and come to us expecting a quick cure. We can be quite firm with these patients, however, and say 'its your problem - own it'. It is easier for us to say that than their own GP.

\section{Dr Ann Connolly}

\section{The urology service}

There are three GPs with a special interest in urology in the PCT: Drs Andy Booth, John Connolly and Sidra. Dr John Connolly undertakes triage of urology outpatient referrals and all three doctors perform flexible cystoscopies. Dr Booth does this at his practice and the others at intermediate care centres.

\section{Urology outpatient triage}

All GPs in the PCT are asked to send their 'nonfast-track' urology referrals to the central referrals office at Westwood Park Clinic, the intermediate care centre. Nonfast-track referrals are patients without signs or symptoms of malignancy. However, patients with haematuria, which is a possible indication of malignancy, are referred to the urology triage team because such patients need a cystoscopy. Referrals to the triage system also include patients with urinary tract infections, prostate problems, impotence and incontinence. All referrals are triaged weekly and decisions are made as to the best course of action for each patient. Again, the aim of the triage system is to make sure consultants only receive 'high quality' referrals; that is, patients who genuinely need to be seen by a specialist and are ready to be seen. Such patients will have had all appropriate investigations carried out and their results reviewed by a GPSI. Patients who do not need to see a consultant may be started on a course of treatment by the GPSI or referred back to their own GP with advice. Patients who obviously require a diagnostic flexible cystoscopy can be given an appointment for the procedure to be carried out by a GPSI.

Many patients presenting with haematuria require a cystoscopy and this can be performed by a GPSI. The central urology referral service has access to the cystoscopy lists of the GPSIs and that of the hospital. Patients are able to access the earliest possible appointment at any location. As mentioned above, haematuria can be a sign of malignancy but a system has been set up whereby patients with this problem are referred to the central urology referrals office instead of the fast-track office. This has been agreed with the urology consultants because the GPSIs can perform cystoscopies more quickly and have demonstrated that they can carry out the procedure competently and interpret the results accurately. This has been verified by audit and subsequent care experience. That is, if a GPSI makes a mistake the patient will eventually be seen in hospital and the error will become apparent.

If the results of a cystoscopy indicate that an operation is necessary GPSIs have direct access to an urgent operation list. Dr John Connolly gave this example:

A patient who presents with urological symptoms, has a cystoscopy and is found to have a bladder tumour can be told by the doctor who performed the procedure. He can also be told what the next part of the treatment is. There isn't any need for that patient to take up a slot or wait for a slot in another clinic because what they need is an operation - so we send the information 
straight to the hospital and they get their operation.

Some patients may attend an appointment with a consultant initially and then be referred to a GPSI for a cystoscopy instead of arranging for the procedure to be carried out at the hospital. This can mean less waiting for the patient and reduces the use of more expensive hospital time.

\section{Bringing together anticipated, explicit and tacit knowledge. What difference does the GPSI urology and cystoscopy service make?}

In the current absence of detailed patient follow-up we report the impressions of two GPSIs interviewed for this paper. We will link these impressions with available data about satisfaction and cost and will consider how the aspirations of the different parties involved in the initiative are being met.

\section{Benefits to patients}

Both Dr Booth and Dr John Connolly are convinced that patients are highly satisfied with their cystoscopy service and prefer being seen in an intermediate care environment. Dr John Connolly explained:

There is no doubt that the intermediate care environment is much less high tech and that the patient's experience is much better.

Before cystoscopies were carried out by GPSIs, patients were admitted as day patients at the hospital:

They (patients) were going down as if they were having an operation. So they were asked to turn up at 7 in the morning and dressed as if for an operation and spent the whole day there - but only had a 2-minute procedure. Not going into hospital makes it less traumatic and we provide better information. Also, everyone is friendly to them. In hospital out-patients everyone is under tremendous pressure and it is hard to be civil as well. In this less pressured environment you are more likely to get the patient explaining what is bothering them or asking the right questions. We have a 90 -year-old man who walks to the cystoscopy out-reach clinic, has his cystoscopy and walks home. That is his cancer surveillance done in half an hour - just like a trip to buy a newspaper.

Dr John Connolly

An independent patient satisfaction survey was carried out at Westwood Park, the centre where Dr John Connolly works (Cummings and Robinson, 2002). The cystoscopy clinic scored highest for 'quality of treatment' and the urology and cystoscopy clinics were among the best scoring clinics for quality of care, compared to the other clinics at the centre. High levels of patient satisfaction with overall care in the centre were also reported.

Dr Booth and Dr John Connolly both feel that GPSI urology and cystoscopy services have reduced waiting times, which is a further important benefit for patients. According to Dr. Booth:

Waiting times for cystoscopies have gone down from 9 months to 4 weeks - within the current guidelines.

\section{Benefits for GPSIs}

Dr Booth felt that he was enjoying greater job satisfaction since becoming a GPSI. He also felt he was making full use of his particular skills. Dr John Connolly explained the impact of the GPSI service on his working life:

My work is more fulfilling now because I feel I can help patients more. As a generalist the patients who come to see me either don't need to see a doctor and we have to pat them on the back and send them out the door - which can be difficult - or they have got something wrong with them but we haven't got the time or the facilities to deal with them. So we have to pack them off somewhere else, like the hospital, to see a specialist. Very often that process is problematic because there are often waits and problems with communication. So now in a small area - urology - there are a group of patients who walk through the door on an average morning who have a problem that I can start to deal with and even if the 
urological problem they are bringing is beyond me e.g. a patient who needs a prostate operation or the removal of a kidney ... I am working very closely with a team of clinicians who are able to do them and I know what checks to do first and I know what to tell the patient. So I feel I can help those patients.

Other benefits that our interviewees believed were related to GPSI services included help with recruitment and retention and help in stopping GP 'burn-out'. In part this is influenced by having more variation within their week and having the stimulation of working alongside specialists in the hospital. GPs also gain more financially by undertaking GPSI work, as compared to working as a clinical assistant at a hospital. It will be important, over time, to assess how far a financial incentive for the doctor drives the development of GPSI services.

\section{Benefits to the practice}

The inclusion of GPSIs can also bring benefits to the practice team. As Dr John Connolly explained:

If you consider that I am working in a team here where many of us have a special interest, it's not just patients with a urology problem that I feel I can help. If they come with neurological problems I can help them because the person in the next room has an interest in neurology and I can learn from him.

GP colleagues from other practices within the PCT can also contact the relevant doctor for advice or a second opinion.

In addition GPSIs can benefit the whole practice financially as Dr Connolly explained:

The money we get for specialist services allows us to deliver care in different ways such as rapid access and practice nurses. It has a knock on effect on practice work and it is a positive effect.

\section{Benefits to the PCT and the NHS}

With more patients receiving treatment from GPSIs will the demand for secondary care in certain disciplines decrease? In the case of urology services it is not as clear-cut as this. According to Dr John Connolly:

We are not mainly about stopping referrals getting through (to secondary care) we are about making good use of the time once they are there and to stop repeat visits. Also to make sure we can make decisions once the patient gets there.

The cost of a flexible cystoscopy performed under a local anaesthetic and carried out by a GPSI in an intermediate care centre is estimated in this PCT to be $£ 121$. This compares with approximately $£ 400$ for the same procedure in hospital. Some patients undergoing a cystoscopy in a hospital may be different from those investigated in primary care but many are comparable. Investigating more patients in primary care should save money:

Some patients will have a cystoscopy in hospital either because they need a general anaesthetic or because it is thought something may have to be done there and then an operation. Obviously a cystoscopy done in an operating theatre with a general anaesthetic will be a lot more expensive. But some diagnostic cystoscopies are still happening in the outpatient clinics and some of the immediate follow-ups. When someone has had bladder cancer they have the op and then the first 2 or 3 check cystoscopies - to check for recurrence in the first few months - will sometimes be done in hospital. But generally the patients we see would be the same sort of patients. A proportion of them are patients presenting with new urological problems including haematuria and another chunk who are follow ups people who have had bladder cancer and are under surveillance for many years. And those are the patients who if they are well and they haven't got a recurrence - which is most of them - they barely need to touch the hospital. This will be a better experience for the patient and should reduce costs.

Dr John Connolly

Apart from reducing waiting times and costs Dr Booth feels that GPSIs, and intermediate care 
services in general, make more appropriate use of health professionals' skills. Nurse practitioners, practice nurses and physiotherapists, for example, develop specialist skills and extend their roles whilst working alongside GPSIs. Dr John Connolly pointed out that GPSIs could also influence the development of the PCT:

(As a GPSI) you also have relevance within the PCT. You can lead on GPSI services and to me that is as much a part of being a GP as anything. You are the patient's advocate and that doesn't mean just the patient in front of you - you can be an advocate for all the patients who use the services.

\section{Discussion}

In this paper, we have summarized the range of GPSI contribution to one PCT and have concentrated on reporting the impression of the doctors delivering the service. As yet there is little systemized recording of patient experience. We have considered the development of GPSI services in terms of the anticipated, explicit and tacit knowledge that is evident. Health services research has to develop a method of evaluating innovative practice while this practice is still in its early days. This is important because initiatives are replicated more quickly than the time scale of conventional evaluative research. In adopting the approach we present here we are contributing to a debate, arising from Polanyi, about knowledge utilization and how different sorts of knowing can come together. It is a debate that has occurred in many disciplines. But we are also engaging with a critique of a too narrow focus on what constitutes evidence that has been developed within primary care. That critique argues that, 'most healthcare issues are multi-dimensional and grounded in individual experience - both the patients and the doctors' (Kernick et al., 1999). The intuitive remains central to the discipline, 'that irreducible something that is the essence of medical care' (Horton, quoted in Feinnman, 2001: 64). What is needed is a new sort of research and acceptance of different sorts of evidence (Tudor Hart, 1997; Salisbury et al., 1998; Alderson, 1998).

Through looking at the experience of GPSI in Bradford South and West we have some indication about how far the potential benefits and possible risks, described in Table 1, are being faced. There is some indication in our interviews that GPSI development might presage a new sort of general practice and the demise of general practitioners. Dr John Connolly's description of a team of primary care staff each with special interests suggests that a patient might come to a practice rather than an individual GP. It would be the practice that is equipped to provide comprehensive primary care. The practice would be staffed by specialists, to whom one would be referred, depending on one's presenting problem. Each person would be seen by a specialist, however, who had closer contact with the history, circumstances and other needs of the patient than a hospital consultant would have. There is also, in the present climate of a shortage of GPs, the possibility of nurse practitioners taking on more of the generalist's role traditionally provided by GPs.

As well as a consideration of the impact on general practice two other areas require further study:

1) What will be the long-term impact on the shape of secondary care?

2) How far is development of GPSIs a precursor to the development of special interests in the rest of the primary care team - 'Practitioners with special interests' might be the more appropriate terminology.

\section{Conclusions}

Bradford South and West PCT was a first wave PCG and PCT and has been recognized as offering a successful innovative model of primary care. Those GPs who have developed as specialists are amongst the most experienced and well trained in the PCT. It is the pattern of innovation that the most able get involved early. The overall effect of specialist GPs needs to be assessed across a wider range of primary care organizations, including ones with less developed processes of governance. There also needs to be scrutiny of the whole system effects of GPSIs and of the long-term clinical outcomes associated with this development.

The potential impact on what we now understand as general practice can be viewed as a benefit or a risk. Key areas might be:

1) Recruitment and retention - will the chance to develop a portfolio career help in securing 
the workforce? Or might one be losing what appealed about general practice - the holistic engagement with a patient over time.

2) Will patients prefer subject expertise over continuity and over ease of access?

3) More fundamentally will the focus on specific areas of problem detract from a medical approach that can locate a person in their biographical, social and geographic context? Primary care is charged with the promotion of health and the reduction of health inequalities, as well as the treatment of ill health. GPSIs might be a distraction from the health aspects of their remit. Further, there is a wish to engage patients and the public more in deciding appropriate health care. A general practice that is not general - but disease focussed - might be disempowering for patients.

We have not only offered a description of the emergence of GPSIs in one PCT, but have also sought to look at a way of bringing together different sorts of knowledge. Wah (1999) estimated that 90 per cent of the knowledge in any organization is embedded and synthesized in people's heads. In their study of 18 family practice teams in America, Aita et al. (2003) found that tacit aspects of data were vital to their understanding of 'the knowledge and behaviour shaping health care practices in complex organizations'. Rashman and Hartley (2002) argue that tacit and explicit knowledge are complementary. We certainly know that much is learned from reflecting on one's own practice and observing and discussing with one's colleagues. That knowing is reinforced by available data. But it is also understood within a belief system. Anticipated knowledge shapes the questions we ask and the reception of the answers we identify. Polyani quotes St Augustine, 'Unless you believe, you shall not understand' (Polyani, 1966: 61).

\section{Acknowledgements}

We are very grateful to Professor Trisha Greenhalgh (Professor of Primary Health Care, University College London) for steering us towards theories of knowledge utilization as a way of structuring our paper.

\section{References}

Aita, V., McIlvain, H., Susman, J. and Crabtree, B. 2003: Using metaphor as a qualitative analytic approach to understand complexity in primary care research. Qualitative Health Research 13, 1419-31.

Alderson. P. 1998: The importance of theories in health care. British Medical Journal 317, 1007-10.

Black, N. 2001: Evidence based policy: proceed with care. British Medical Journal 323: 2759.

Bowling, A. and Bond, M. 2001: A national evaluation of specialists' clinics in primary care settings. British Journal of General Practice 51, 264-69.

Commission for Health Improvement. 2003: Clinical governance review. Bradford South and West PCT. London: CHI.

Cummings, J. and Robinson, D. 2002: Westwood Park Clinic patient survey: final report. Brighton: The Institute for Employment Studies.

Department of Health. 1989: Working for patients. Cm 555. London: HMSO.

Department of Health. 1997: The new NHS. Modern, dependable. London: The Stationery Office.

Department of Health. 2001a: The NHS Plan. A plan for investment, a plan for reform. London: The Stationery Office.

Department of Health. 2001b: Shifting the balance of power within the NHS - securing delivery. London: Department of Health.

Department of Health/Royal College of General Practitioners (RCGP). 2002: Implementing a scheme for general practitioners with special interests. London: RCGP.

Dhillon, R. and Rout, D. 2002: General practitioners with special interests (GPSIs). British Medical Journal 324, 91.

Feinnman, J. 2001: Too much information. The Observer Magazine 11 November, 63-64.

Fitzmaurice, D.A., Hobbs, F.D.R., Murray, E.T., Allan, T.F. and Rose, P.E. 2000: Oral anticoagulation management in primary care with the use of computerized decision support and near patient testing. Randomized control trial. Archives of Internal Medicine: 160, 2343-48.

Gerada, C., Wright, N. and Keen, J. 2002: The general practitioner with a special interest: new opportunities or the end of the generalist practitioner? British Journal of General Practice 52, 796-98.

Gamble, J. 2001: Modelling the invisible: the pedagogy of craft apprenticeship. Studies in Continuing Education 3, $185-200$.

Hansen, M., Nohria, N. and Tierney, T. 1999: What's your strategy for managing knowledge? Harvard Business Review 77, 106-87.

Jarvis, P. 1999: The practitioner researcher: developing theory from practice. San Francisco, CA: Jossey-Bass.

Jones, R. and Bartholomew, J. 2002: General practitioners with special clinical interests: a cross sectional survey. British Journal of General Practice 52, 833-34. 
Kernick, D., Stead, J. and Dixon, M. 1999: Moving the research agenda to where it matters (editorial). British Medical Journal 319, 206-207.

NHS Executive. 2003: The NHS Beacon Services Initiative and Nye Bevan awards. www.doh.gov.uk/nhsinfo/pages/ quality/beacon.htm, (Retrieved 4 July 2003).

Polanyi, M. 1966: The tacit dimension. London: Routledge and Kegan Paul.

Popper, K.R. 1959: Logic of scientific discovery. New York: Routledge.

Rashman, L. and Hartley, J. 2002: Leading and learning: knowledge transfer in the Beacon council scheme. Public Administration 80, 523-42.

Richardson, C. 2002: GPs ready to specialise: will the advent of specialist GPs benefit primary care? Medeconomics May, 35-36.

Royal College of General Practitioners and Royal College of Physicians of London. 2001: General practitioners with special interests. London: RCGP and RCP.

Royal College of General Practitioners. 2001: Implementing a scheme for general practitioners with special interests. London: RCGP.

Rosen, R. and Jones, R. 2003: A study of general practitioner specialist clinics to evaluate their impact on access to specialist care, costs and patient and clinician satisfaction. Research outline: www.sdo.lshtm.ac.uk/access.htm\#rosen2 (Retrieved 4 July 2003).

Rosen, R., Stevens, R. and Jones, R. 2003: General practitioners with special clinical interests. British Medical Journal 327, 460-62.

Salisbury, C., Bosanquet, N., Wilkinson, E., Bosanquet, A. and Hasler, J. 1998: The implementation of evidence based medicine in general practice prescribing. British Journal of General Practice 48, 1849-51.

Sanderson, D., Limber, C., Eldred, C. and Harrison, K. 2003: To the ENT degree. Health Service Journal 113, 26-27.

Small, N. 2003. Knowledge, not evidence, should determine primary care practice. Clinical Governance 8, 191-99.

Tudor Hart, J. 1997: What evidence do we need for evidence based medicine? Journal of Epidemiology and Community Health 51, 623-29.

Wah, L. 1999: Making knowledge stick. Management Review May, 17-26.

Wyatt, J. 2001: Management of explicit and tacit knowledge. Journal of the Royal Society of Medicine 94, 6-9. 